\title{
Balanced steady-state free precession cardiovascular magnetic resonance imaging of edema in reperfused acute myocardial infarcts - a translational study in animals and men
}

\author{
Andreas Kumar*1, Nirat Beohar², Jain M Arumana², Debiao Li², \\ Matthias G Friedrich ${ }^{1}$ and Rohan Dharmakumar ${ }^{2}$
}

Address: ${ }^{1}$ University of Calgary, Calgary, AB, Canada and ${ }^{2}$ Northwestern University, Chicago, IL, USA

* Corresponding author

from 13th Annual SCMR Scientific Sessions

Phoenix, AZ, USA. 2I-24 January 2010

Published: 21 January 2010

Journal of Cardiovascular Magnetic Resonance 20 I0, I2(Suppl I):O76 doi:I0.I I86/I532-429X-I2-SI-O76

This abstract is available from: http://jcmr-online.com/content/I2/SI/O76

(C) 2010 Kumar et al; licensee BioMed Central Ltd.

\section{Introduction}

Edema imaging is usually performed using T2-weighted STIR imaging. We hypothesized that balanced steadystate-free-precession (b-SSFP) sequences also have sensitivity to detect edema in acute reperfused ST-elevation myocardial infarction (STEMI).

\section{Methods}

The study was conducted in mini-pigs and patients with acute reperfused STEMI. In the mini-pigs, myocardial infarction was created by angiographically guided balloon occlusion of the proximal left circumflex coronary artery for ninety minutes. The animals were imaged on day 2 or 3 after experimental ischemia/reperfusion.

For the clinical arm, patients from the coronary care unit were included within four days after successful percutaneous coronary intervention for STEMI.

All CMR images were obtained on a $1.5 \mathrm{~T}$ clinical system (Siemens, Germany), using the following sequences in a short axis orientation (slice thickness $10 \mathrm{~mm}, 0$ gap): conventional cine SSFP, T2-STIR (patients only), late enhancement (10 min after injection of $0.2 \mathrm{mmol} / \mathrm{kg} \mathrm{Gd}$ DTPA), applying typical sequence parameters. Semiquantitative threshold-based image analysis of late enhancement images (LE) identified the infarct region and infarct area was calculated. In the infarction zone and remote myocardium, on corresponding T2-STIR and SSFP images, signal and contrast, as well as the area of edema were measured and compared using paired t-tests, correlation statistics.

\section{Results}

In 13 pigs, the area of high SSFP signal and the area of LE correlated with $R=0.83$. Signal intensity in the infarction zone on SSFP was higher than in the remote zone (203.5 \pm 28.7 (edema) vs. $148+/-19.8$ (remote), $\mathrm{p}<0.001$ ), with a contrast-to-noise ratio of $37 \pm 13$.

In 16 patients (age $57 \pm 8$ years, 3 female, STEMI location anterior/septal $n=9$, lateral $n=1$, inferior $n=6$ ) on T2STIR images, the signal intensity in the infarct zone was higher than signal in remote myocardium $(351 \pm 109$ (edema) vs. $222 \pm 81$ (remote), p < 0.001), and the same was observed on SSFP $(252 \pm 35$ (edema) vs. $163 \pm 32$ (remote), $\mathrm{p}<0.001)$. Contrast-to-noise ratio efficiency $\left(\mathrm{CNR}_{\text {eff }}\right)$, corrected for voxel size, was not different between T2-STIR and b-SSFP $\left(\mathrm{CNR}_{\text {eff }}\right.$ T2-STIR $77 \pm 37$ vs. $\mathrm{CNR}_{\text {eff }} \mathrm{b}$-SSFP $65 \pm 30, \mathrm{p}=0.30$ ). The edematous volumes as measured by T2-STIR correlated well with the volumes measured by b-SSFP $(\mathrm{R}=0.78, \mathrm{p}<0.001)$, but on T2-STIR were little larger than on b-SSFP (volume of edema T2STIR $6.4 \pm 2.1 \mathrm{ml}$ vs. SSFP $4.9 \pm 1.9 \mathrm{ml}, \mathrm{p}=0.03)$. Infarct volumes on LGE were $4.2 \pm 1.6 \mathrm{ml}$ Figure 1 . 


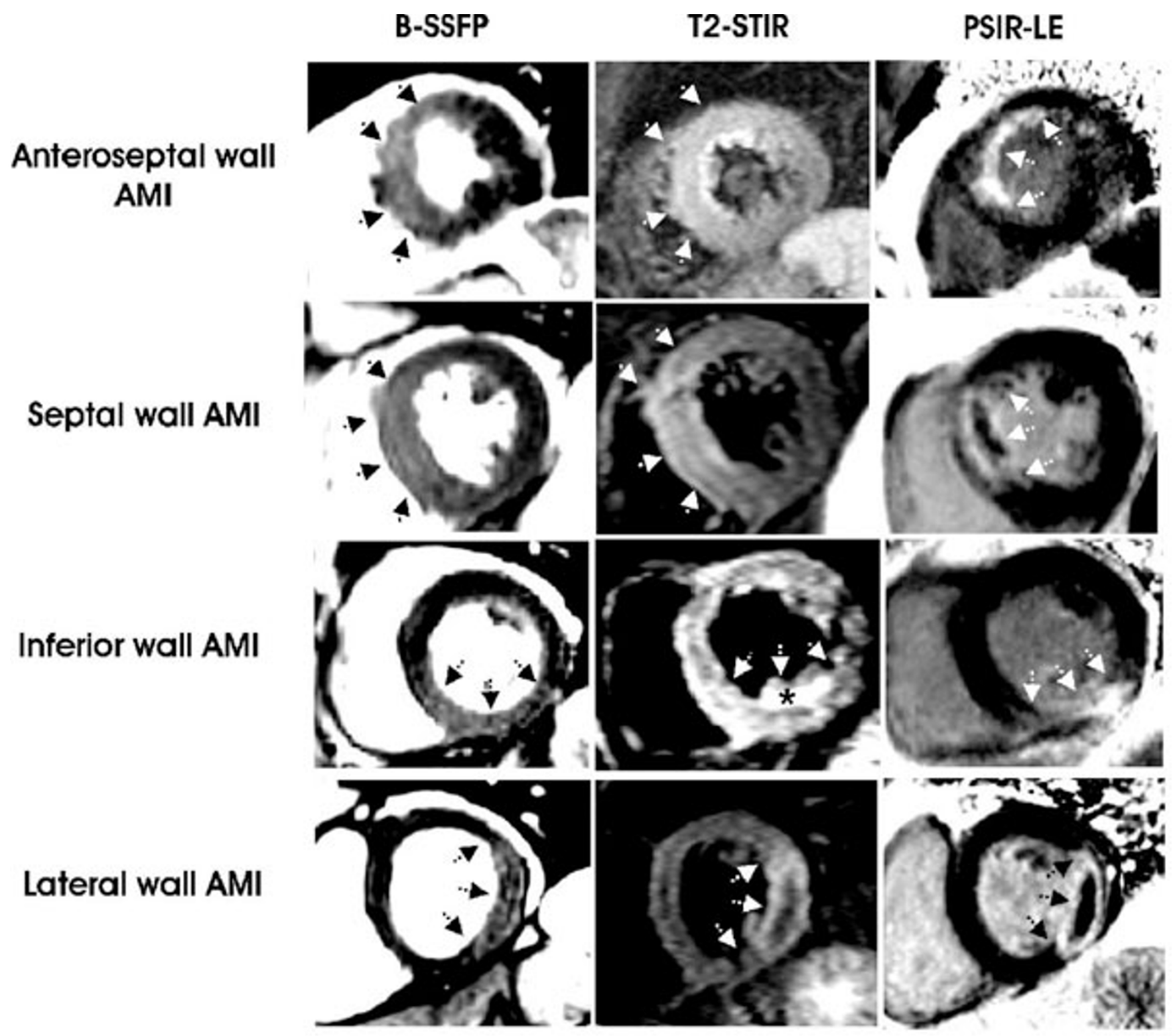

Figure I

A representative set of edema weighted B-SSFP and T2-STIR images with difference STEMI locations in patients. Note the close correspondence between hyperintense territories identified by B-SSFP and T2-STIR acquisitions and the confirmation of infarcted territories on late-enhancement images (PSIR-LE).

\section{Conclusion}

Myocardial Edema in both, experimental and clinical STEMI, can be detected using SSFP imaging with contrast similar to T2-STIR.
Publish with Bio Med Central and every scientist can read your work free of charge

"BioMed Central will be the most significant development for disseminating the results of biomedical research in our lifetime. " Sir Paul Nurse, Cancer Research UK

Your research papers will be:

- available free of charge to the entire biomedical community

- peer reviewed and published immediately upon acceptance

- cited in PubMed and archived on PubMed Central

- yours - you keep the copyright 